\title{
ESTIMATION OF ASSET ACCUMULATION OF THE PROPOSED SLOVENIAN MANDATORY-FUNDED PENSION PILLAR
}

\author{
T. ŠKERLJ, G. DOLINAR and D. MRAMOR \\ (Received: 28 February 2001; revision received: 22 May 2001; \\ accepted: 18 August 2001)
}

\begin{abstract}
This paper analyses the impact of the introduction of a proposed mandatory earnings-related fully-funded pension scheme, named as the second pillar, on the accumulation of pension-funds assets and possibly on the capital market development in Slovenia. First, the dynamic simulation model is developed to estimate the accumulated pension-funds assets as a percentage of GDP in each future time period under the assumption of certainty. It is followed by the assumptions and estimates of the data used for independent variables and the results obtained by implementing the model for the period of 25 years. Relaxing the assumption of certainty, the paper proceeds with estimations of accuracy of the results with three methods. It is concluded, that the estimated level of accumulated pension-funds assets in GDP 25 years after the introduction of the reform will be approximately $40 \%$ and comparable to the level in countries with developed capital markets. Also, the accuracy of the estimate is surprisingly good. It is therefore expected that besides other effects, the introduction of this pension scheme would have an important impact on the development of the Slovenian capital market.
\end{abstract}

Keywords: fully-funded pension system, pension reform, accumulated assets, Slovenia, simulation.

JEL classification index: G23, C15.

\section{INTRODUCTION}

Important demographic changes (i.e. ageing population, decreasing natality, etc.) have in many countries made their established pay-as-you-go pension schemes financially not viable on a long-term basis. ${ }^{1}$ Therefore, alternative pension arrange-

A pay-as-you-go pension scheme is a social contract of mandatory intra-temporal, inter-generational transfers from workers to pensioners, backed by an implicit government debt of promise to contributing worker cohorts that will benefit from future worker contributions once they retire (Corsetti et al., 1995).

Corresponding author: Dušan Mramor, University of Ljubljana, Faculty of Economics, Department of Finance, Kardeljeva ploščad 17, 1000 Ljubljana, Slovenia. E-mail: dusan.mramor@uni-lj.si 
ments have been developed and introduced with pension reforms, primarily in the form of mandatory or voluntary fully-funded schemes. ${ }^{2}$ The economic effects of these reforms are numerous and usually depend on the level of accumulated pension-funds assets.

Regarding the impact of pension reform on the aggregate level of savings, US and UK empirical evidence suggests that growth in funded pension schemes is only partly offset by declines in discretionary personal savings. Almost thirty years ago, Feldstein (1974) published an influential empirical study, in which he claimed that social security significantly depresses private savings. Despite the subsequent appearance of numerous studies analysing these issues, no consensus view concerning the impact of social security on savings has yet emerged. ${ }^{3}$ Recent studies by Arrau and Schmidt-Hebbel (1993), Feldstein (1977), Threadgold (1980), and others referred to in Munnel and Yohn (1992) suggest an increase in personal savings of around 0.35 results from every unit increase in pension-fund assets. The cost to the public sector of the tax incentives given to pension-funds, however, provides a partial offset to this effect on savings at an economy-wide level, thereby reducing the benefit to around 0.2. Nevertheless, savings depend on a large number of factors, such as the demographic structure of the population, income per capita, income growth, and the nature of credit markets as well as pension systems. One must be cautious about drawing any conclusions concerning the overall effect of pension-funds on aggregate savings. Therefore, pensionfunds may have a minor effect on total savings, but their crucial effect may be the indirect one on the composition of savings with the increased share of long-term financial savings (Davis, 1995 and Vittas, 1992).

In this respect, the increased role of capital markets is of great importance and in all countries, and especially those in transition to market economies, pension reform holds significant potential for the development of their capital markets. This would result not only from the increased long-term financial resources, provided by the accumulation of pension-fund assets and stimulating the development of bond and equity markets, but also from the positive force for innovation for corporate governance, and for privatisation. The recent study of Holzmann (1996) highlights the theoretical underpinnings of the excellent economic effects claimed for

2 A fully-funded and earnings-related pension scheme is a mandatory saving system, which forces workers to save part of their wage income for old age. The average return on old-age saving is determined by the market interest rate. Under this condition, fully-funded scheme provides a close link between worker contributions and benefits: pensions are actuarially fair for each individual (Arrau and Schmidt-Hebbel, 1993).

3 An overview of articles about the effect of social security on personal savings can be found in Bernheim and Levin (1989). 
the Chilean pension reform of 1981 and presents empirical data and preliminary econometric testing of its conjectured growth, capital formation, and saving effects. The results of his empirical study are consistent with most of the claims; in particular, there is a close relationship between the development of pension-funds and financial markets, rendering them deeper, more liquid, and more competitive.

As the value of accumulated pension-funds assets is one of the most important factors determining the economic consequences of pension reforms, the impact of the introduction of funded pension schemes on this accumulation and related economic consequences have been widely analysed. Most empirical studies are ex-post, like Davis (1995), Chand and Jaeger (1996) and Vittas (1995), where the level (and growth) of accumulation of pension-fund assets expressed as percentage of the GDP is estimated for several countries. These authors find that most countries with large pension-fund sectors tend to have well-developed securities markets, while others (for example Germany, Italy) do not.

Contrary to most research, we try to estimate the future accumulation of the most important part of pension-fund assets in Slovenia, if proposed pension reform is implemented. On the basis of comparison of the estimated future level of accumulated pension-funds in Slovenia with levels in countries with developed capital markets we draw conclusion concerning the impact of pension reform on the development of the capital market in Slovenia. ${ }^{4}$

The pension reform proposal for Slovenia suggests the introduction of a so-called multipillar pension system. The reform should include a correction of the existing pay-as-you-go pillar and the introduction of two additional funded pillars. The second pillar is to be mandatory, and the third pillar voluntary. Both should be (1) fully-funded schemes with individualised accounts, (2) defined contributions schemes, where the pension (lifetime annuity) depends on the accumulated savings increased by returns on invested savings and (3) privately managed.

The second pillar is a mandatory earnings-related fully-funded pension arrangement, which forces workers to save part of their wage income for old age and represents far the most important funded pillar. It is expected to create the majority of pension-funds assets - the accumulation of these assets is less uncertain, and it is expected to have biggest macroeconomic effects. For example, one can expect that the mandatory contributions of all employees (and their employers) ${ }^{5}$ will have much bigger overall effect on aggregate savings than voluntary pension-funds

4 The Slovenian capital market is approximately ten years old, it has relatively low level of efficiency and liquidity (Deželan, 1996; Mramor, 2000).

5 In the current pay-as-you-go system and according to the White Paper of the Pension Reform in Slovenia (MDDSZ, 1997) the contributions are/will be paid as a percentage of the gross salary, whereby the employer pays $8.85 \%$ and the employee $15.5 \%$. 
schemes, where increased pension savings of individuals mainly in higher income or wealth classes will be more or less offset by declines in their discretionary personal savings and by the cost of tax incentives. ${ }^{6}$ These are the reasons for the paper focusses on the impact of the mandatory second pillar on future accumulation of pension-funds assets and leaves aside much less predictable impact of the voluntary third pillar.

The pension reform proposes that 25 years from the introduction of the second pillar will be the period of (mainly) pension-funds asset accumulation and only after this period will inflows and outflows in the form of pensions become more balanced and the level of accumulated pension-funds assets will change only gradually. As we are primarily interested in the relative level of accumulated pensionfunds assets, we restricted our analysis to this 25 -year period of asset accumulation.

The contents of the paper are as follows. We first develop the model for estimating the accumulated pension-funds assets in each of the 25 years as a percentage of GDP. The model is based on certainty assumption and includes the inflows (e.g. contributions paid by employees/employers, return on accumulated assets) and the outflows of pension-funds (e.g. pensions paid to pensioners, administration and marketing costs). It is followed by the assumptions and estimates of the data used for independent variables and the results obtained by implementing the model up to the year 2025. As future values of independent variables are more or less uncertain, the paper proceeds with estimations of measurement errors. Three different methods of estimating measurement errors are considered: the linear method, the simulation method and the method of possible values.

The estimated level of accumulated mandatory pension-funds assets in GDP 25 years after the introduction of the reform is comparable to the level in countries with developed capital markets. Also, the accuracy of the estimate is surprisingly good. It is therefore concluded that the introduction of the mandatory second fully-funded pension pillar is expected to have important impact on the development of Slovenian capital market.

\section{THE MODEL}

In this section we develop a dynamic simulation model, which provides an estimate for the quantitative effects of the introduction of a mandatory fully-funded pension scheme on the accumulation of pension-fund assets. The dependent vari-

6 One can also expect that the impact on the capital market development will be smaller, as discretionary savings of these wealthier individuals are at least partly already invested on the capital market.

Acta Oeconomica 51 (2000/2001) 
able of our model is the coefficient of the accumulated pension-fund assets at the end of year $t$ to the GDP of the $t$. The quantity of all assets in the second pillar at the end of year $t$ depends on the quantity of assets at the end of year $t-1$, on the average real return on these assets invested on the capital market in year $t,{ }^{7}$ on contributions inflows in year $t$, on the pensions outflows in year $t$, and on the administration and marketing costs in year $t$. Mathematically we can express the total accumulated assets of pension-funds by the end of year $t$ as:

$$
B_{t}=B_{t-1}\left(1+i_{t}\right)+P_{t}-O_{t}-A M_{t}
$$

where

$B_{t} \quad=$ accumulated assets of pension-funds by end of year $t$;

$P_{t} \quad=$ contributions paid by employees/employers in year $t$ (inflow);

$O_{t} \quad=$ pensions paid to pensioners in year $t$ (outflow);

$A M_{t}=$ administration and marketing costs of pension-funds in year $t$;

$i_{t} \quad=$ average real rate of return of accumulated assets of the pension-funds in year $t$.

Since the contribution rate for the second pillar is the same for all employees/employers, we can express the yearly contributions paid by employees/employers as follows:

$$
P_{t}=c \cdot A_{t} \cdot W_{t}
$$

where

$c=$ contribution rate for the second pillar;

$A_{t}=$ number of employees included in the second pillar in year $t$;

$W_{t} \quad$ average gross wage of employee.

The administration and marketing costs can be expressed as a share of the contributions as follows:

$$
A M_{t}=a m_{t} \cdot P_{t}
$$

where

$a m_{t}=$ administration and marketing costs in year $t$ as a percentage of contributions paid.

7 To simplify the model we use a conservative estimation approach ignoring the return on the real increase of the assets during the year. 
Substituting (2) and (3) into (1) we obtain:

$$
B_{t}=B_{t-1}\left(1+i_{t}\right)+c \cdot A_{t} \cdot W_{t} \cdot\left(1-a m_{t}\right)-O_{t}
$$

The share of accumulated assets of pension-funds in the GDP in year $t$ is then:

where

$$
b_{t}=\frac{B_{t-1}\left(1+i_{t}\right)+c \cdot A_{t} \cdot W_{t}\left(1-a m_{t}\right)-O_{t}}{Y_{t}}
$$

$b_{t}=$ accumulated assets of pension-funds as percentage of GDP by the end of year $t$

$Y_{t}=$ GDP in year $t$.

Therefore, in order to calculate the share of accumulated assets of pensionfunds in the GDP by the end of year $t$, we need to estimate the initial quantity of assets at the beginning of year $t_{o}$ and, for each year from year $t_{o}$ until year $t_{n}$, the average real rate of return, the contribution rate for the second pillar, the number of employees included in the second pillar, the average gross wage, the administration and marketing costs in relation to contributions paid, the pensions paid and the GDP.

From these, the contribution rate for the second pillar $(c)$ is defined by law and is normally constant for a longer period of time. The number of employees included in the second pillar $\left(A_{t}\right)$ in each year and the pensions paid to pensioners $\left(O_{t}\right)$ in each year are estimated by demographic factors. The administration and marketing costs in relation to contributions paid $\left(a m_{t}\right)$ are normally higher in the first years of operation (start-up costs, economies of scale, etc.). The remaining variables are assumed to depend on the growth rate of GDP in year $t$ in the following way.

The GDP in year $t$ equals

$$
Y_{t}=Y_{t-1}\left(1+y_{t}\right)
$$

where

$y_{t}=$ growth rate for GDP in year $t$.

We assumed that the gross wage growth is proportional to the growth rate of GDP where the proportionality coefficient is constant. Then

$$
W_{t}=W_{t-1}\left(1+k y_{t}\right)
$$

where

$k=$ regression coefficient of the growth rate of gross wages to $y_{t}$. 
If we now rewrite equation (5) using (6) and (7) we get:

$$
b_{t}=\frac{B_{t-1}\left(1+i_{t}\right)+c \cdot A_{t}\left(1+k \cdot y_{t}\right) W_{t-1}\left(1-a m_{t}\right)-O_{t}}{Y_{t-1}\left(1+y_{t}\right)}
$$

This can be simplified to

$$
b_{t}=b_{t-1} \frac{1+i_{t}}{1+y_{t}}+c \cdot A_{t} \cdot \omega_{t}\left(1-a m_{t}\right)-o_{t}
$$

where

$\omega_{t}=\frac{W_{t}}{Y_{t}}$, the share of gross wages in the GDP in year $t$ and is computed by using the relation $\omega_{t}=\frac{1+k y_{t}}{1+y_{t}} \omega_{t-1}$ and

$o_{t}=\frac{O_{t}}{Y_{t}} \quad$ is the proportion of pensions paid from the second pillar in GDP in year $t$.

The input variables of our model are thus only: the initial values $Y_{t o}$ and $W_{t o}$, the constants $c$ and $k$ and, for each year $t$, the values $i_{t}, A_{t}, y_{t}, O_{t}$ and $a m_{t}$.

\section{DATA SET}

To estimate accumulated assets of pension-funds as percentage of GDP by end of the year 2025 using the model represented by equation (8), the values for the following variables have to be obtained or estimated: ${ }^{8}$

$$
c ; W_{98} ; Y_{98} ; A_{00}, \ldots, A_{25} ; O_{00}, \ldots, O_{25} ; a m_{00}, \ldots, a m_{25} ; y_{99}, \ldots, y_{25} ; k ;
$$

Table 1 summarises the values for the basic variables of our model. These are the contribution rate, the average yearly gross wage for the year 1998 and the value of GDP for the year 1998. While the value of the contribution rate is defined in the proposal for the pension reform, data for wages and GDP are known for the year 1998 and used as a base for estimating starting year (2000) values of these variables.

8 The period of estimation is from year 2000 to 2025. 
Table 1

Basic starting assumptions for the accumulation of pension-funds assets model

Year of introduction of funded pension system

Contribution rate as a percentage of gross wage

Average yearly gross wage for year 1998

GDP for year 1998

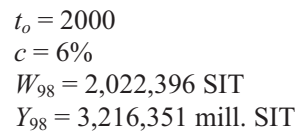

Source: BS, 1999, p. 59, 61, 62; ZPIZ, 1997 and MDDSZ, 1997.

As values for basic demographic variables (number of employees included in the second pillar $-A_{t}$ and outflows from pension-funds $-O_{t}$ ) we use estimates presented in Table 6 in columns $5\left(A_{t}\right)$ and $7\left(O_{t}\right)$ that we derived from the World Bank simulation model ("Simulation model for Slovenia", 1997, electronic version). ${ }^{9}$ These estimates comprise the future 25 -year period and are based on the data and assumptions presented in Table 2.

Table 2

Data and assumptions for demographic estimates

\begin{tabular}{lc}
\hline Number of employees end of 1997 & 837,428 \\
Number of registered unemployed end of 1997 & 128,572 \\
Number of labour force end of 1997 & 966,000 \\
Number of pensioners end of 1997 & 449,794 \\
Fertility rate in 1997 & 1.25 \\
Lifetime expectancy at birth in 1997 (in years) & 71.0 \\
- For men & 78.6 \\
- For women & \\
\hline
\end{tabular}

Source: SURS, 1998.

We assume that only employees under 35 years of age will be included in the new multipillar system and that the average retirement age will be 60 for women and men alike. This means that the number of employees included in the second pillar $\left(A_{t}\right)$ after the year 2025 will be the same as the number of all employees contributing to the pension system.

The administration and marketing costs in year t as percentage of contributions paid $\left(\mathrm{am}_{t}\right)$ strongly depend on such factors as the number of pension-funds and the associated competition and economies of scale, the transferability of pension rights, etc. Decentralised pension systems cannot reach the same economies

9 The views of the World Bank on pension reform are summarised in Averting the Old Age Crisis, (World Bank, 1994), where a three-pillar pension system is recommended. 
of scale as centralised systems and therefore result in higher transactions and marketing costs. On the other hand, decentralised pension systems lead to a higher operating efficiency. This may explain why the operating costs in 1990 in Chile amounted to $15 \%$ of contributions and in Singapore only to $0.5 \%$ (World Bank, 1994). ${ }^{10}$ There is also a difference in costs between defined-contribution and defined-benefit plans, with the former being lower. For example the administrative costs for the US pension-funds are $8.3 \%$ of contributions for defined-benefit plans and $4 \%$ for defined-contribution plans (Davis, 1995). Based on experiences of pension-funds in other countries we will assume that the administration and marketing costs for Slovene pension-funds will amount to $15 \%$ of the contributions during the whole period. This may be a relatively conservative estimate, but it takes into consideration the past (negative) experience with the introduction of investment funds in Slovenia, which were set up in 1991 when mass privatisation began and which have had very high administrative and marketing costs. Therefore:

$$
a m_{00}, \ldots, a m_{25}=15 \% .
$$

Our forecasts for the future growth rates of GDP $\left(y_{t}\right)$ are based on the past economic developments in Slovenia and on the forecasts for the near future by the Economic Institute of the Faculty of Law (EIPF, 1999, p. 32), that are presented in Table 3.

\section{Table 3}

Growth rates of GDP in Slovenia and in the EU (\%)

\begin{tabular}{lcc}
\hline Year & $\begin{array}{c}\text { Growth rates of GDP } \\
\text { in Slovenia }\end{array}$ & $\begin{array}{c}\text { Growth rates of GDP } \\
\text { in the EU }\end{array}$ \\
\hline 1993 & 2.8 & -0.4 \\
1994 & 5.3 & 2.8 \\
1995 & 4.1 & 2.4 \\
1996 & 3.1 & 1.6 \\
1997 & 3.2 & 2.5 \\
1998 & 3.9 & 2.6 \\
$1999 *$ & 4.1 & 2.1 \\
$2009^{*}$ & 3.5 & 3.0 \\
$2001 *$ & 4.5 & 3.0 \\
$2002 *$ & 5.0 & n.a. \\
$2003 *$ & 4.4 & n.a. \\
$2004 *$ & 3.6 & n.a. \\
\hline
\end{tabular}

* Forecast (for Slovenia by Economic Institute of the Law Faculty, for the EU by European Commission). Source: BS, 1997, pp. 60 and 62; EIPF, 1999, p. 32 and European Commission, 1999, pp. 450-451.

10 A detailed empirical analysis of the Chilean pensions system is shown in Shah (1996). 
As a comparison we can see in the second column of Table 3 the growth rates of GDP for the European Union countries. As Slovenia is undergoing a transitional period with fast economic development since the year 1991, its GDP growth rates are higher in comparison to the growth rates of EU countries. After the year $2002 \mathrm{a}$ smoothing of the economic growth is expected for Slovenia and in the long run it is expected that the GDP growth will approach the EU growth values of $3 \%$. We are aware that this may be a conservative approach. Therefore:

$$
\begin{aligned}
& y_{99}=4.1 \%, \quad y_{00}=3.5 \%, \quad y_{01}=4.5 \%, \quad y_{02}=5.0 \%, \\
& y_{03}=4.4 \%, \quad y_{04}=3.6 \%, \quad y_{05}, \ldots, \quad y_{25}=3.0 \% .
\end{aligned}
$$

For the constant $k$, the regression coefficient of the growth rate of gross wages to the GDP growth rate, we assume that the gross wages will grow slightly slower than the GDP.

\section{Table 4}

Growth rates of real gross wages in Slovenia and in the EU (\%)

\begin{tabular}{lcc}
\hline Year & $\begin{array}{c}\text { Growth rates of real } \\
\text { gross wages in Slovenia }\end{array}$ & $\begin{array}{c}\text { Growth rates of real } \\
\text { gross wages in the EU }\end{array}$ \\
\hline 1993 & 13.3 & 0.2 \\
1994 & 3.6 & -0.2 \\
1995 & 4.4 & 0.2 \\
1996 & 4.9 & 0.5 \\
1997 & 3.2 & 0.7 \\
1998 & 1.6 & 0.7 \\
1999 & 3.3 & 1.4 \\
$2000^{*}$ & 3.2 & 1.2 \\
$2001^{*}$ & 3.1 & 1.4 \\
$2002^{*}$ & 3.5 & n.a. \\
$2003^{*}$ & 3.2 & n.a. \\
$2004^{*}$ & 3.0 & n.a. \\
\hline
\end{tabular}

*Forecast (for Slovenia by Economic Institute of the Law Faculty, for the EU by European Commission).

Source: BS, 2000, p. 72; European Commission, 1999, pp. 450-451 and EIPF, 1999, p. 32.

As it can be seen from Tables 3 and 4 the past wage growth was usually higher than the GDP growth. The reason for this can be found in the fact that Slovenia is going through the transition process, which is associated with high wage growth rates. As wage differential is substantial between Slovenia and the EU countries, we expect further higher relative growth of wages in Slovenia than in EU countries when Slovenia joins EU (as opposed to real GDP growth). Therefore we fore- 
cast that the wage growth will be closely linked to the GDP growth and assume the correlation coefficient to be nine tenths,

$$
k=0.9 \text {. }
$$

The yearly real rate of return on the accumulated pension-fund assets $\left(i_{t}\right)$ is highly dependent on the design of the pension system. Since centralised public managers chosen by political leaders and decentralised private managers chosen by individual savers in a competitive environment face different incentives and, more importantly very different constraints, investment outcomes may be very different under these two arrangements. The figure below shows the differences between the real rates of return of publicly managed pension-funds and privately managed pension-funds in different countries in the period between 1980 and 1990. In contrast to publicly managed funds, privately managed funds in which employees choose their fund managers, are usually not required to accept below-market returns and are less likely to encourage deficit spending by governments, which enables privately managed funds to earn much higher rates of return than their public counterparts.

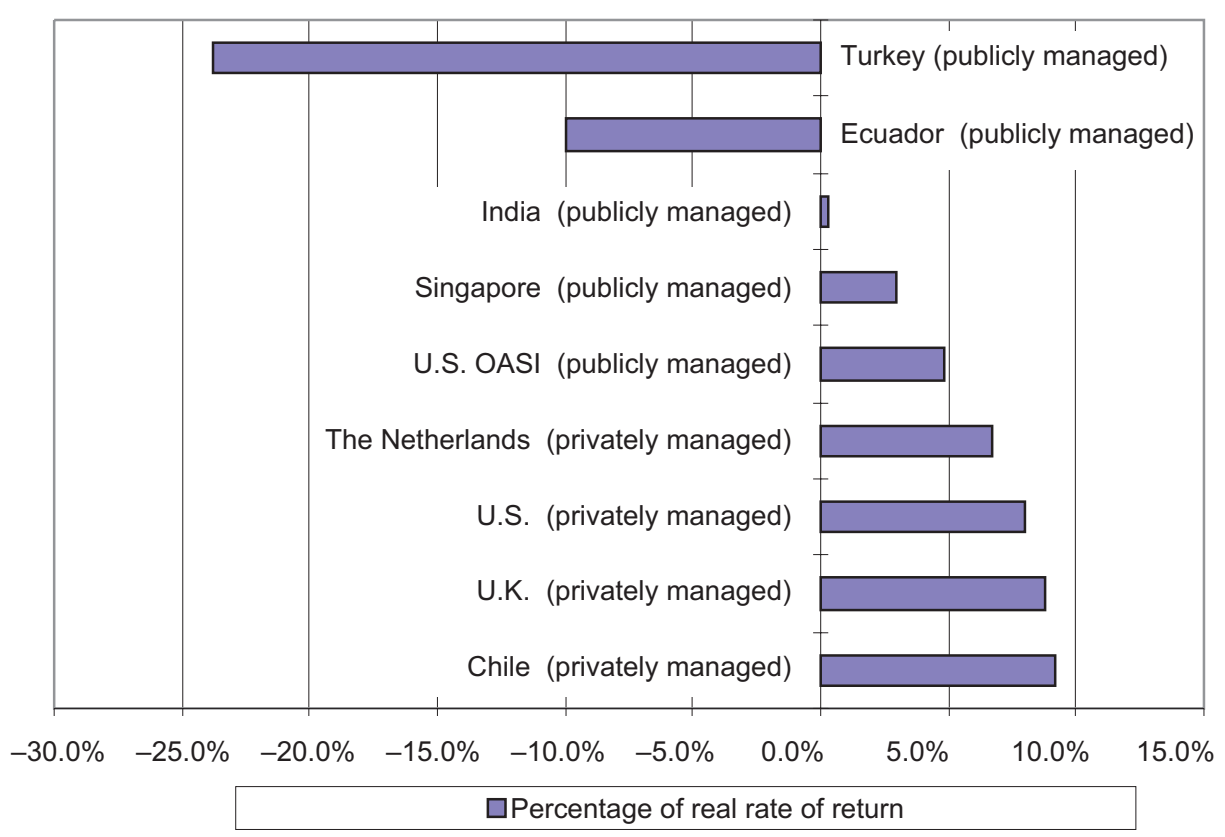

Average annual real rates of return for selected pension-funds in different countries in the 1980s (Source: World Bank, 1994, p. 95.) 
Davis (1995) also presents the returns on pension-funds' portfolios between 1967 and 1990. As shown in Table 5, pension-funds in the UK earned the highest real return over the period and those in Sweden, Switzerland, Canada, and the USA the lowest. Davis comes to the same conclusion concerning the relative real rates of return of privately managed funds and publicly managed funds. Based on the data for the UK and the USA (comparing effects of ownership and management methods within the same markets) he found that local-government funds obtain lower returns than private funds (Davis, 1995, p. 151).

\section{Table 5}

Rates of return and their standard deviation of pension funds portfolios in different countries in the period from 1967 to $1990(\%)$

\begin{tabular}{lcc}
\hline Country & $\begin{array}{c}\text { Mean of annual real rates } \\
\text { of return }\end{array}$ & $\begin{array}{r}\text { Standard } \\
\text { deviation }\end{array}$ \\
\hline USA & 2.2 & 11.9 \\
UK & 5.8 & 12.5 \\
Germany & 5.1 & 4.4 \\
Japan & 4.0 & 9.4 \\
Canada & 1.6 & 9.8 \\
Netherlands & 4.0 & 6.0 \\
Sweden & 0.2 & 7.6 \\
Denmark & 3.6 & 12.7 \\
Switzerland & 1.5 & 6.4 \\
Australia & 1.6 & 14.7 \\
\hline
\end{tabular}

Source: Davis, 1995, p. 146.

Since the Slovene pensions funds should be privately managed with government regulation (MDDSZ, 1997, pp. 182-195) and based on the experience of other countries, we have set the average real rate of return for the Slovene pension-funds to be equal to GDP growth rate over the whole period of analysis. Therefore:

$$
i_{t}=y_{t}
$$

\section{Estimation and results}

Based on these assumptions Table 6 shows the elements and results (column 11) of the calculation of the share of accumulated pension-funds assets in GDP for each year from 2000 to 2025 . 
Data in Table 6 show that in the first few years the accumulated assets of the pension-funds increase rapidly. This is the transition phase, which will last only in the period from year 2000 until 2025 when the number of employees included in the second pillar $\left(A_{t}\right)$ will constantly increase until every employee is included. On the other hand the outflows $\left(O_{t}\right)$ will be very low in the first years, arising only as a consequence of early deaths and disabilities. There will be no retirees. That is why at the beginning of the implementation of the fully-funded pension-funds the inflows are much higher than the outflows. However the difference between the inflows and the outflows becomes smaller with each further year until all flows balance at the end of the introduction period. After this period the outflows for old-age pensions and normal deaths become more important. The projection shows that the share of accumulated pension-funds assets in GDP reaches a value slightly above $40 \%$ in the year 2025 .

\section{ROBUSTNESS TEST}

The accuracy of the estimations of accumulated assets for the first year depends mostly on the quality of the model, since the values of the independent variables are known. The accuracy of the estimations for the following years is increasingly dependent on the estimated values of independent variables.

In the robustness tests we focussed on the two economic variables that have in our opinion the biggest impact on the estimations, growth rate of GDP $\left(y_{t}\right)$, and relative administration and marketing costs $\left(a m_{t}\right)$. Namely, demographic variables are relatively reliable while the remaining economic variables are either determined by law or dependent on the chosen variables.

We assume that the two parameters $y_{t}$ and $a m_{t}$ are random variables, normally distributed around expected values $E\left(y_{t}\right)$ and $E\left(a m_{t}\right)$ with given relative half-width of confidence intervals $r d_{y_{t}}$ and $r d_{a m_{t}}$ corresponding to probability $\alpha=0.95$. The values $r d_{y_{t}}$ and $r d_{a m_{t}}$ represent the proportion of the expected value by which the random variables deviate from their expected values with probability $\alpha=0.95$. The intermediate dependent variables $Y_{t}, W_{t}$, and $B_{t}$ and the final dependent variable of the model $b_{t}$, as functions of $y_{t}$ and $a m_{t}$ are thus also random variables.

We will use three methods to estimate the relative half-width $r d$ of the confidence interval of the variable $b_{t}$, which represents a bound that the relative error of the model will not exceed with probability $\alpha$. A brief description of the methods is in the Appendix. The expected values $E\left(y_{t}\right)$ and $E\left(a m_{t}\right)$ are taken to be the values computed by the model, the relative half-width $r d_{y_{1}}$ is estimated to be $30 \%$ and the relative half-width $r d_{a m_{t}}$ to be $25 \%$ for the whole period. We have set the variability of the GDP growth rate to $30 \%$ based on the past variability of GDP growth for 
Table 6

Estimations of the share of accumulated pension-funds assets in the GDP in the period from year 1999 to 2025

\begin{tabular}{|c|c|c|c|c|c|c|c|c|c|c|c|}
\hline Year & $\begin{array}{l}\text { GDP } \\
\text { growth } \\
\text { rate }\end{array}$ & $\begin{array}{c}\text { GDP } \\
\left(10^{9} \mathrm{SIT}\right)\end{array}$ & $\begin{array}{c}\text { Yearly } \\
\text { real } \\
\text { gross } \\
\text { wages } \\
\left(10^{3} \mathrm{SIT}\right)\end{array}$ & $\begin{array}{l}\text { No. of em- } \\
\text { ployees } \\
\text { included } \\
\text { in the 2nd } \\
\text { pillar in } 10^{3}\end{array}$ & $\begin{array}{l}\text { Yearly } \\
\text { contributions } \\
\text { paid into } \\
\text { 2nd pillar } \\
\left(10^{9} \mathrm{SIT}\right)\end{array}$ & $\begin{array}{c}\text { Yearly } \\
\text { outflows } \\
\text { from } \\
\text { pension-funds } \\
\left(10^{6} \mathrm{SIT}\right)\end{array}$ & $\begin{array}{l}\text { Portion of } \\
\text { admin. and } \\
\text { mark. costs }\end{array}$ & $\begin{array}{l}\text { Admin. } \\
\text { and mark. } \\
\text { costs } \\
\left(10^{9} \mathrm{SIT}\right)\end{array}$ & $\begin{array}{c}\text { Yearly } \\
\text { accumulated } \\
\text { assets } \\
\left(10^{9} \mathrm{SIT}\right)\end{array}$ & $\begin{array}{c}\text { Yearly } \\
\text { accumulated } \\
\text { assets/GDP }\end{array}$ & $\begin{array}{l}\text { Increase } \\
\text { of yearly } \\
\text { accumu- } \\
\text { lated } \\
\text { assets/GDP }\end{array}$ \\
\hline$t$ & $y_{t}$ & $Y_{t}$ & $W_{t}$ & $A_{t}$ & $P_{t}=c A_{t} W_{t}$ & $O_{t}$ & $a m_{t}$ & $A m_{t}=a m_{t} P_{t}$ & $B_{t}$ & $b_{t}=\frac{B_{t}}{Y_{t}}$ & $\frac{\Delta B_{t}}{Y_{t}}$ \\
\hline (1) & (2) & (3) & (4) & (5) & (6) & (7) & (8) & (9) & (10) & (11) & (12) \\
\hline 1999 & 0.035 & 3329 & 2.086 & 0 & 0.0 & 0 & 0.00 & 0.00 & 0.00 & 0.000 & 0.00 \\
\hline 2000 & 0.045 & 3479 & 2.171 & 327 & 42.6 & 0 & 0.15 & 6.39 & 36.20 & 0.010 & 0.010 \\
\hline 2001 & 0.045 & 3635 & 2.258 & 352 & 47.7 & 280 & 0.15 & 7.15 & 78.09 & 0.021 & 0.012 \\
\hline 2002 & 0.050 & 3817 & 2.360 & 369 & 52.3 & 287 & 0.15 & 7.84 & 126.13 & 0.033 & 0.013 \\
\hline 2003 & 0.044 & 3985 & 2.454 & 405 & 59.6 & 294 & 0.15 & 8.94 & 182.06 & 0.046 & 0.014 \\
\hline 2004 & 0.036 & 4128 & 2.533 & 431 & 65.5 & 602 & 0.15 & 9.83 & 243.69 & 0.059 & 0.015 \\
\hline 2005 & 0.030 & 4252 & 2.601 & 456 & 71.2 & 618 & 0.15 & 10.68 & 310.89 & 0.073 & 0.016 \\
\hline 2006 & 0.030 & 4380 & 2.672 & 480 & 76.9 & 949 & 0.15 & 11.54 & 384.67 & 0.088 & 0.017 \\
\hline 2007 & 0.030 & 4511 & 2.744 & 504 & 83.0 & 973 & 0.15 & 12.45 & 465.76 & 0.103 & 0.018 \\
\hline 2008 & 0.030 & 4647 & 2.818 & 526 & 88.9 & 1.662 & 0.15 & 13.34 & 553.67 & 0.119 & 0.019 \\
\hline 2009 & 0.030 & 4786 & 2.894 & 548 & 95.2 & 1.704 & 0.15 & 14.27 & 649.45 & 0.136 & 0.020 \\
\hline 2010 & 0.030 & 4930 & 2.972 & 569 & 101.5 & 2.096 & 0.15 & 15.22 & 753.09 & 0.153 & 0.021 \\
\hline 2011 & 0.030 & 5077 & 3.052 & 589 & 107.9 & 2.506 & 0.15 & 16.18 & 864.87 & 0.170 & 0.022 \\
\hline 2012 & 0.030 & 5230 & 3.135 & 608 & 114.4 & 3.303 & 0.15 & 17.15 & 984.72 & 0.188 & 0.023 \\
\hline 2013 & 0.030 & 5387 & 3.219 & 626 & 120.9 & 4.138 & 0.15 & 18.14 & 1112.90 & 0.207 & 0.024 \\
\hline 2014 & 0.030 & 5548 & 3.306 & 643 & 127.6 & 6.169 & 0.15 & 19.13 & 1248.55 & 0.225 & 0.024 \\
\hline 2015 & 0.030 & 5715 & 3.396 & 659 & 134.3 & 7.114 & 0.15 & 20.14 & 1393.02 & 0.244 & 0.025 \\
\hline 2016 & 0.030 & 5886 & 3.487 & 674 & 141.0 & 8.913 & 0.15 & 21.15 & 1545.77 & 0.263 & 0.026 \\
\hline 2017 & 0.030 & 6063 & 3.582 & 686 & 147.4 & 12.042 & 0.15 & 22.11 & 1705.40 & 0.281 & 0.026 \\
\hline 2018 & 0.030 & 6245 & 3.678 & 698 & 154.0 & 14.046 & 0.15 & 23.11 & 1873.45 & 0.300 & 0.027 \\
\hline
\end{tabular}


(Table 6 continuted)

Estimations of the share of accumulated pension-funds assets in the GDP in the period from year 1999 to 2025

\begin{tabular}{|c|c|c|c|c|c|c|c|c|c|c|c|}
\hline Year & $\begin{array}{l}\text { GDP } \\
\text { growth } \\
\text { rate }\end{array}$ & $\begin{array}{c}\text { GDP } \\
\left(10^{9} \mathrm{SIT}\right)\end{array}$ & $\begin{array}{c}\text { Yearly } \\
\text { real } \\
\text { gross } \\
\text { wages } \\
\left(10^{3} \mathrm{SIT}\right)\end{array}$ & $\begin{array}{l}\text { No. of em- } \\
\text { ployees } \\
\text { included } \\
\text { in the } 2 \text { nd } \\
\text { pillar in } 10^{3}\end{array}$ & $\begin{array}{c}\text { Yearly } \\
\text { contributions } \\
\text { paid into } \\
\text { 2nd pillar } \\
\left(10^{9} \mathrm{SIT}\right)\end{array}$ & $\begin{array}{c}\text { Yearly } \\
\text { outflows } \\
\text { from } \\
\text { pension-funds } \\
\left(10^{6} \mathrm{SIT}\right)\end{array}$ & $\begin{array}{l}\text { Portion of } \\
\text { admin. and } \\
\text { mark. costs }\end{array}$ & $\begin{array}{l}\text { Admin. } \\
\text { and mark. } \\
\text { costs } \\
\left(10^{9} \mathrm{SIT}\right)\end{array}$ & $\begin{array}{c}\text { Yearly } \\
\text { accumulated } \\
\text { assets } \\
\left(10^{9} \mathrm{SIT}\right)\end{array}$ & $\begin{array}{c}\text { Yearly } \\
\text { accumulated } \\
\text { assets/GDP }\end{array}$ & $\begin{array}{l}\text { Increase } \\
\text { of yearly } \\
\text { accumu- } \\
\text { lated } \\
\text { assets/GDP }\end{array}$ \\
\hline$t$ & $y_{t}$ & $Y_{t}$ & $W_{t}$ & $A_{t}$ & $P_{t}=c A_{t} W_{t}$ & $O_{t}$ & $a m_{t}$ & $A m_{t}=a m_{t} P_{t}$ & $B_{t}$ & $b_{t}=\frac{B_{t}}{Y_{t}}$ & $\frac{\Delta B_{t}}{Y_{t}}$ \\
\hline (1) & (2) & (3) & (4) & (5) & (6) & (7) & (8) & (9) & (10) & (11) & (12) \\
\hline 2019 & 0.030 & 6432 & 3.778 & 711 & 161.1 & 17.014 & 0.15 & 24.17 & 2049.62 & 0.319 & 0.027 \\
\hline 2020 & 0.030 & 6625 & 3.880 & 721 & 167.8 & 17.887 & 0.15 & 25.17 & 2235.88 & 0.337 & 0.028 \\
\hline 2021 & 0.030 & 6824 & 3.984 & 730 & 174.5 & 24.751 & 0.15 & 26.18 & 2426.54 & 0.356 & 0.028 \\
\hline 2022 & 0.030 & 7028 & 4.092 & 739 & 181.4 & 31.477 & 0.15 & 27.21 & 2622.07 & 0.373 & 0.028 \\
\hline 2023 & 0.030 & 7239 & 4.202 & 748 & 188.6 & 36.116 & 0.15 & 28.29 & 2824.93 & 0.390 & 0.028 \\
\hline 2024 & 0.030 & 7456 & 4.316 & 759 & 196.5 & 42.942 & 0.15 & 29.48 & 3033.79 & 0.407 & 0.028 \\
\hline 2025 & 0.030 & 7680 & 4.432 & 762 & 202.6 & 47.052 & 0.15 & 30.40 & 3250.00 & 0.423 & 0.028 \\
\hline
\end{tabular}


Slovenia and on the variability in EU countries, the group of which seems to be ready to accept Slovenia as a member in the probably not too distant future. Based on experiences of pension-funds in other countries, we have set the variability of administration and marketing costs to $25 \%$.

\section{Linear method}

In this method, the dependent variable is estimated by a linear first-order approximation that is again normally distributed. For each $t$ we first compute $r d_{Y_{t}}, r d_{W_{t}}$, and $r d_{B}$, using equation (A6). Finally, we compute $r d_{t}$ which represents the upper bound ( $-r d_{t}$ represents the lower bound) that the relative error of the model will not exceed with probability 0.95 in year $t$. All calculations were made with the programming package Mathematica and the calculated values are presented in Table 7, column 2.

\section{Simulation method}

Using a programming package with a built-in function $r n d n(E, \sigma)$ that generates random values of a normally distributed random variable with expected value $E$ and standard deviation $\sigma$, we can perform a simulation of the model. Values of the random variable $y_{t}$ are generated with calls of the function $\operatorname{rndn}\left[E\left(y_{t}\right), \sigma_{y_{t}}\right]$, and, similarly, values of $a m_{t}$ are generated with calls of the function $\operatorname{rndn}\left[E\left(a m_{t}\right), \sigma_{a m_{t}}\right]$, where the standard deviations $\sigma_{y_{t}}$ and $\sigma_{a m_{t}}$ are computed from $r d_{y_{t}}$ using equation (A4) and the relation

$$
d_{X}=r d_{X} \cdot E(X) .
$$

The initial values $Y_{98}$ and $W_{98}$ are known. The simulated values of the variables $Y_{t}$ and $W_{t}$ for all subsequent years are then obtained by inserting the generated values of $y_{t}$ into equations (6) and (7).

The initial value $B_{99}$ is zero. The simulated values of $B_{t}$ are computed recursively using equation (4) and, finally, the simulated values $b_{t}$ are computed using the relation $b_{t}=\frac{B_{t}}{Y_{t}}$.

This algorithm is repeated until a significant sample is obtained. We used a sample of 4000 values. ${ }^{11}$ The confidence intervals are then computed according to

11 Increasing the number of values in the sample over 4000 did not yield significantly different results. 
the algorithm described in the Appendix. The results of the calculation are presented in Table 7 in column 3.

\section{Method of possible values}

Due to the recursive definition of our model we will partially modify the method described in the Appendix. Instead of computing the maximum value of $b_{t}$ on the product of the confidence intervals of the independent variables, we define a new function max $b_{t}$ such that for the same value of the independent variable $y_{t}$ the value of $b_{t}$ is less than or equal to the value of $\max b_{t}$ for all values of all other independent variables within the confidence intervals. This is done in the following way. First, since $Y_{t}$ and $W_{t}$ are both increasing functions of the variable $y_{t}$ we obtain the maximal values max $Y_{t}$ and $\max W_{t}$ at the point $y_{t}=E\left(y_{t}\right)\left(1+r d_{y}\right)$, and the minimal values $\min Y_{t}$ and $\min W_{t}$ at the point $y_{t}=E\left(y_{t}\right)\left(1-r d_{y_{t}}\right)$. Next, the function $\max B_{t}$ is computed recursively by:

$$
\begin{gathered}
\max B_{99}=0, \text { and } \\
\max B_{t}\left(y_{t}\right)=\max B_{t-1}\left(1+y_{t}\right)+c \cdot A_{t} \cdot \max W_{t-1}\left(1+k \cdot y_{t}\right)\left(1-\min a m_{t}\right)-O_{t}
\end{gathered}
$$

since $B_{t}$ is an increasing function of $B_{t-1}$ and $W_{t-1}$, and a decreasing function of $a m_{t}$, so the largest value of $B_{t}$ is obtained when the values of $B_{t-1}$ and $W_{t-1}$ are the largest possible, and the value of $a m_{t}$ is the smallest possible. Finally, let

$$
\max b_{t}\left(y_{t}\right)=\frac{\max B_{t-1}\left(1+y_{t}\right)+c \cdot A_{t} \cdot \max W_{t-1} \cdot\left(1+k \cdot y_{t}\right)\left(1-\min a m_{t}\right)-O_{t}}{\left(1+y_{t}\right) \min Y_{t}} .
$$

For a constant value of $y_{t}$, max $b_{t}$ is always greater than or equal to $b_{t}$. In the same manner we define also function $\min b_{t}$. The minimal value of $\min b_{t}$ and the maximal value of max $b_{t}$ with respect to $y_{t}$ (which are either in a local extreme on the interval $\left[E\left(y_{t}\right)\left(1-r d_{y_{t}}\right), E\left(y_{t}\right)\left(1-r d_{y_{t}}\right)\right]$ or in a boundary point of the interval) represent our estimate for the lower and upper bound of the interval in which the value of $b_{t}$ lies with probability at least 0.95 . The procedure described above was programmed in Mathematica and the results of the calculations are presented in Table 7 column 4. 
Table 7

Estimates of possible relative deviations of actual shares of accumulated pension-fund assets in GDP from the predicted values (at $95 \%$ probability level) obtained by three methods (\%)

\begin{tabular}{|c|c|c|c|}
\hline \multirow[t]{2}{*}{ Year } & \multicolumn{3}{|c|}{ Relative upper error bounds estimated by } \\
\hline & Linear method & Simulation method & $\begin{array}{l}\text { Method of possible } \\
\text { values }\end{array}$ \\
\hline 1999 & 0.0 & 0.0 & 0.0 \\
\hline 2000 & 4.9 & 4.3 & 6.5 \\
\hline 2001 & 4.1 & 3.1 & 6.9 \\
\hline 2002 & 4.1 & 2.5 & 8.7 \\
\hline 2003 & 4.1 & 2.2 & 11.3 \\
\hline 2004 & 4.1 & 2.0 & 13.6 \\
\hline 2005 & 4.1 & 1.8 & 15.6 \\
\hline 2006 & 4.1 & 1.7 & 17.3 \\
\hline 2007 & 4.2 & 1.6 & 19.0 \\
\hline 2008 & 4.2 & 1.5 & 20.8 \\
\hline 2009 & 4.3 & 1.5 & 22.6 \\
\hline 2010 & 4.4 & 1.4 & 24.4 \\
\hline 2011 & 4.5 & 1.4 & 26.2 \\
\hline 2012 & 4.6 & 1.3 & 28.0 \\
\hline 2013 & 4.7 & 1.3 & 29.8 \\
\hline 2014 & 4.7 & 1.3 & 31.7 \\
\hline 2015 & 4.8 & 1.2 & 33.6 \\
\hline 2016 & 4.9 & 1.2 & 35.6 \\
\hline 2017 & 5.0 & 1.1 & 37.5 \\
\hline 2018 & 5.1 & 1.1 & 39.5 \\
\hline 2019 & 5.2 & 1.1 & 41.5 \\
\hline 2020 & 5.3 & 1.1 & 43.6 \\
\hline 2021 & 5.4 & 1.0 & 45.7 \\
\hline 2022 & 5.5 & 1.0 & 47.9 \\
\hline 2023 & 5.6 & 1.0 & 50.1 \\
\hline 2024 & 5.7 & 1.0 & 52.3 \\
\hline 2025 & 5.8 & 1.0 & 54.7 \\
\hline
\end{tabular}

\section{INTERPRETATION OF RESULTS}

Our analysis is divided into two parts. In the first part we develop a model for the estimation of the quantitative effects on the accumulated pension-fund assets and empirically implement it thereafter based on sociodemographic and macroeconomic assumptions and estimates for the Slovene economy.

In Table 6 columns 10 and 11 show the results of the implementation of our model without uncertainty. In column 10 we can see the yearly-accumulated assets in absolute values and in column 11 the yearly accumulated assets in relation to the GDP for the years 2000-2025. The projections show that the value of accumulated assets in relation to the GDP constantly increases in the first 25 years up to a value of slightly above $40 \%$. 
Table 8

Comparison of accumulated assets of pension funds, real rates of return and administration and marketing costs for selected countries

\begin{tabular}{lccc}
\hline & $\begin{array}{c}\text { Real rate of return } \\
\text { (average 1980-1990) }\end{array}$ & $\begin{array}{c}\text { Administration and } \\
\text { marketing costs as \% } \\
\text { of annual contribution in 1990 }\end{array}$ & $\begin{array}{c}\text { Assets of pension } \\
\text { funds as \% of GDP } \\
\text { in 1991 }\end{array}$ \\
\hline USA & 8.0 & 4.0 & 51 \\
U.K. & 8.8 & n.a. & 60 \\
Netherlands & 6.7 & n.a. & 46 \\
Chile & 9.2 & 15.4 & 26 \\
Singapore & 3.0 & 0.5 & 76 \\
Malaysia & 4.6 & 2.0 & n.a. \\
\hline
\end{tabular}

Source: Davis, 1995, p. 6, World Bank, 1994, pp. 95, 224 and 130.

Table 8 shows that countries with mature fully-funded pension systems (USA, U.K., The Netherlands, Singapore) reach values of accumulated assets in relation to the GDP around $60 \%$, only The Netherlands is slightly below $50 \%$. Chile, whose pension system is still in the transition phase, has reached in two decades from the introduction of the fully-funded pension-funds a value of pension-fund assets of $26 \%$ in relation to the GDP. Therefore, if we compare the results for the Slovene economy with other countries, we can see that our projections are quite realistic.

Column 12 in Table 6 shows the relation of the yearly increase of accumulated pension-fund assets in relation to the GDP. This "relative delta" starts at $1 \%$ per year and reaches a value of almost 3\% per year in the year 2025. The question which is inseparably associated with this result is whether this potential increase results in additional savings or it is just a redistribution between pension saving and other types of private savings. If a funded pension system is associated with a higher level of savings than a pay-as-you-go pension system, the higher investment and growth that results would be perhaps its most compelling advantage. Pension funds tend to boost the supply of long-term funds to capital markets and contribute to financial innovation and modernisation of market structures. Nevertheless, there are several scenarios where pension assets would have a lower impact on the development of the Slovene capital market. For example, if most of pension assets are invested in foreign financial assets, or in non-marketable government securities. This link between introduction of fully-funded pension system and national savings is an important topic and we consider it as an area for further research for the case of Slovenia.

The second part contains a description of three statistical methods for error estimation. In all three methods we assume that our dependent variables are normally 
distributed random variables. The first, linear method, shows that our forecasts are increasingly reliable up to year 2005, but slightly less reliable in the following years (see Table 7, column 2). This is a consequence of the fact that the absolute amount of all assets $B_{t}$ in the second pillar increases in this introductory period and a significant share of the increase is due to the "demographic" variables $A_{t}$ and $O_{t}$ that were assumed to be constant and thus do not contribute to the estimated error. Therefore, the relative deviations $r d_{B}$ of the variable $B_{t}$ drop very fast in the beginning, but start increasing gradually as the errors accumulate in the later years. Since we use the calculated values of $r d_{B}$ in order to get $r d_{b_{t}}$, this is true for the $r d_{b_{1}}$ estimates as well.

In the second method, the normal distributions of the independent variables are simulated and a sample is computed from which we estimate the distribution function of the dependent random variable. The estimates computed by this method (Table 7, column 3) give even smaller relative deviations of the dependent variable from its expected values than those of the linear method.

In the last method, we compute the minimum and maximum values of the dependent variable on the product of the confidence intervals that correspond to the chosen $\alpha=0.95$ The dependent variable will have value on the interval between the minimal and the maximal value with probability at least $\alpha$. In our model, estimates and not precise values of the minimum and maximum are computed. The estimate for the error obtained by this method is somewhat weaker - the method shows that we can claim with at least $95 \%$ certainty that the dependent variable will not deviate from its expected value for more than $55 \%$.

A comparison of all three methods for estimating the error of the model shows that our model is surprisingly stable. It should be mentioned, though, that this result is partly a consequence of the assumption that some of the variables, which substantially affect the value of the dependent variable (mostly demographic variables) are, at least in the introductory period of the first 25 years after introducing the mandatory second pillar, constant for every year.

\section{CONCLUSION}

This paper analyses the impact of the introduction of pension reform in Slovenia on the accumulation of pension-fund assets in relation to the GDP, focussing on the mandatory fully-funded system - the so-called second pillar of the three-pillar system.

By developing and applying a dynamic simulation model for the Slovene economy we calculated the quantitative effects of the introduction of a fully-funded pension system on the accumulation of pension-fund assets based on selected 
sociodemographic, macroeconomic and administrative assumptions. The projections, which were done for the first 25 years show that the value of accumulated assets in relation to the GDP constantly increases and reaches a value slightly above $40 \%$. As can be seen in Table 8 , this result is comparable with other countries' where a fully-funded pension system was implemented.

The most important question which arises concerning macroeconomic growth is whether these additional accumulated assets result in additional national savings or they cause only a redistribution between pension saving and other types of private savings. This link between pensions and saving is a broadly investigated topic that would need to be further analysed for Slovenia.

It should be mentioned that in the final version of the law, the proposed mandatory second pillar (as described in this article) for Slovenia has been rejected and instead a voluntary second pillar has been introduced. This will certainly cause several difficulties with the pension system. It will be interesting to compare the actual accumulated assets of the voluntary second pillar to the forecasts for the mandatory second pillar calculated in this article.

To test the stability of our model we applied three methods: the linear method, the estimation by simulation, and the method of possible values. When comparing the results of the three methods, we realised that all of them produce similar estimates for the year 2000 . With $95 \%$ probability the maximum deviations are $\pm 4,9 \%$ by the linear method, $\pm 4,3 \%$ with the estimation by simulation, and $\pm 6,5 \%$ by the method of possible values. The results are as expected, namely that the method of possible values gives us the roughest, while the simulation produces the best estimation. However, the estimates by the three methods differ more and more in the following years since the errors are reflected in the result for the following year. In the year 2025 we can forecast with $95 \%$ probability that maximum deviations would be $\pm 5.8 \%$ by the linear method, $\pm 1 \%$ by the estimation by simulation, and $\pm 55 \%$ with the method of possible values. These results show that our model is very stable when considering the roughness of the method of possible values. Such a stability is the mainly the consequence of the quite realistic assumption that the variables, which affect the value of the dependent variable (mostly demographic variables) are constant in the period discussed. 


\section{APPENDIX}

\section{Linear method ${ }^{12}$}

Let the dependent variable $Y$ be a random variable, which is a differentiable function of $n$ random variables $X_{1}, \ldots X_{n}$

$$
Y=f\left(X_{1}, \ldots, X_{n}\right)
$$

that are normally distributed around given expected values $E\left(X_{1}\right), \ldots, E\left(X_{n}\right)$ with given standard deviations $\sigma_{1}, \ldots, \sigma_{n}$ and correlation coefficients $\rho_{i j}$ between $X_{i}$ and $X_{j}$, where $i, u=1, \ldots, n$. The distribution of the dependent random variable $Y$ is determined by the distributions of the explanatory variables $X_{1}, \ldots, X_{n}$, but it is in general not normal if $f$ is nonlinear and it can be difficult to compute. Therefore, we simplify the function $f\left(x_{1}, \ldots, x_{n}\right)$ with a linear approximation

$$
f_{l}\left(x_{1}, \ldots, x_{n}\right)=a+b_{1} x_{1}+\ldots+b_{n} x_{n},
$$

and calculate the probability distribution of the approximated variable

$$
Y_{l}=f_{l}\left(X_{1}, \ldots, X_{n}\right) .
$$

The approximating linear function $f_{l}$ can be obtained from the Taylor polynomial of the first order around the expected values of the explanatory random variables:

$f_{l}\left(X_{1}, \ldots, X_{n}\right)=f\left[E\left(X_{1}\right), \ldots, E\left(X_{n}\right)\right]+\sum_{i=1}^{n} f_{x_{i}}\left[E\left(X_{1}\right), \ldots, E\left(X_{n}\right)\right] \cdot\left[X_{i}-E\left(X_{i}\right)\right]$, where

$f_{x_{i}}$ is a partial derivative of the function $f\left(x_{1}, \ldots x_{n}\right)$ with respect to the variable $x_{i}$.

The linear approximate $Y_{l}$ is a normally distributed random variable, since it is a linear function of normally distributed random variables $X_{1}, \ldots, X_{n}$, with expected value

$$
E\left(Y_{l}\right)=E\left[f_{l}\left(X_{1}, \ldots, X_{n}\right)\right]=f_{l}\left[E\left(X_{1}\right), \ldots, E\left(X_{n}\right)\right]=f\left[E\left(X_{1}\right), \ldots, E\left(X_{n}\right)\right]
$$

and variance

$$
\begin{aligned}
\sigma_{l}^{2}= & \sum_{i=1}^{n} f_{x_{i}}^{2}\left[E\left(X_{1}\right), \ldots, E\left(X_{n}\right)\right] \sigma_{i}^{2}+ \\
& +\sum_{\substack{j=1 \\
i \neq j}}^{n} f_{x_{i}}\left[E\left(X_{1}\right), \ldots, E\left(X_{n}\right)\right] f_{x_{j}}\left[E\left(X_{1}\right), \ldots, E\left(X_{n}\right)\right] \rho_{i j} \sigma_{i} \sigma_{j}
\end{aligned}
$$

12 See also Coleman et al. (1989), p. 188.

Acta Oeconomica 51 (2000/2001) 
where

$\rho_{i j} \quad=$ correlation coefficient between variables $X_{i}$ and $X_{j}$;

$\sigma_{i}^{2}=$ variance of the variable $X_{i}$.

If the variables $X_{1}, \ldots, X_{n}$ are pairwise independent then the correlation coefficients $\rho_{i j}$ are zero if $i \neq j$, and the variance formula can be simplified to

$$
\sigma_{l}^{2}=\sum_{i=1}^{n} f_{x_{i}}^{2}\left[E\left(X_{1}\right), \ldots, E\left(X_{n}\right)\right] \sigma_{i}^{2} .
$$

Once the expected value and variance of a normally distributed variable $X$ is known, the confidence interval for a given probability $\alpha, 0<\alpha \leq 1$ can be determined (usually $\alpha$ is $0.99,0.95,0.90$ or 0.66 ). The confidence interval is the interval with the centre at $E(X)$ and width $2 d$ such that the value of $X$ lies in this interval with probability $\alpha$, i.e.

$$
\alpha=P\left[E\left(Y_{l}\right)-d \leq Y_{l}<E\left(Y_{l}\right)+d\right]=\Phi\left(\frac{d}{\sigma_{l}}\right)-\Phi\left(\frac{-d}{\sigma_{l}}\right)=2 \Phi\left(\frac{d}{\sigma_{l}}\right)-1,
$$

where $\Phi$ is the standardised normal distribution function. From the above equation we can compute the half-width of the confidence interval

$$
d=\Phi^{-1}\left(\frac{\alpha+1}{2}\right) \cdot \sigma_{l} .
$$

If, for a given $\alpha$, we write

$$
t_{\alpha}=\Phi^{-1}\left(\frac{\alpha+1}{2}\right)
$$

then the half-widths $d_{i}$ of the confidence intervals of the independent variables $X_{i}$ equal

$$
d_{i}=t_{\alpha} \cdot \sigma_{i},
$$

where $i=1, \ldots, n$. Multiplying equation (A2) by $t_{\alpha}^{2}$ we get

$$
\sigma_{l}^{2} t_{\alpha}^{2}=\sum_{i=1}^{n} f_{x_{i}}^{2}\left[E\left(X_{1}\right), \ldots, E\left(X_{n}\right)\right] \sigma_{i}^{2} t_{\alpha}^{2},
$$

and from here we see that the half-width of the confidence interval of $Y_{l}$ is

$$
d^{2}=\sum_{i=1}^{n} f_{x_{i}}^{2}\left[E\left(X_{1}\right), \ldots, E\left(X_{n}\right)\right] d_{i}^{2} .
$$


So, if we know that, for each $i=1, \ldots n$, the explanatory random variable $X_{i}$ has value in the interval $\left[E\left(X_{i}\right)-d_{i}, E\left(X_{i}\right)+d_{i}\right]$ with the probability $\alpha$, we know that the random variable $Y_{l}$ has value in the interval

$$
\left[E\left(Y_{l}\right)-d, E\left(Y_{l}\right)+d\right]
$$

with the probability $\alpha$, where $d$ is computed from equation (A5).

Dividing equation (A5) by $E\left(Y_{l}\right)^{2}$ we obtain the following formula expressing the relative half-width of the confidence interval of the variable $Y_{l}$ in terms of the relative half-widths of the confidence intervals of the independent variables $X_{1}, \ldots X_{n}$ :

where

$$
r d^{2}=\sum_{i=1}^{n}\left(\frac{f_{x_{i}}\left[E\left(X_{1}\right), \ldots, E\left(X_{n}\right)\right]}{\frac{E\left(Y_{l}\right)}{E\left(X_{i}\right)}}\right)^{2} r d_{i}^{2},
$$

$$
r d=\frac{d}{E\left(Y_{l}\right)} \text { and } r d_{i}=\frac{d_{i}}{E\left(X_{i}\right)} .
$$

If we know that, for each $i=1, \ldots, n$, the explanatory variable $X_{i}$ deviates with probability $\alpha$ from its average value $E\left(X_{i}\right)$ by the proportion $r d_{i}$ of its average value, then formula (A6) gives the proportion $r d$ of the average value $E\left(Y_{l}\right)$ by which $Y_{l}$ will deviate from $E\left(Y_{l}\right)$ with probability $\alpha$.

\section{Simulation method}

Assuming that the explanatory random variables $X_{1}, \ldots, X_{n}$ are random variables with known probability distributions, the error of the model can also be estimated by computer simulation. If the random variables $X_{i}, i=1, \ldots, n$, are normally distributed, we can use any program package with a built-in program function, for example $r n d n(E, \rho)$, generating values of a normally distributed random variable with the expected value $E$ and the variance $\rho^{2}$. Every time the function $r n d n(E, \rho)$ is called, it computes a value, and the probability distribution of the computed values after a large enough number of function calls is normal with expected value $E$ and the variance $\rho^{2}$. In our analysis, the programming package Mathematica was used.

If the parameters $X_{1}, \ldots, X_{n}$ are normally distributed random variables with given expected values $E\left(X_{1}\right), \ldots, E\left(X_{n}\right)$ and variances $\sigma_{1}^{2}, \ldots, \sigma_{n}^{2}$, and if 


$$
Y=f\left(X_{1}, \ldots, X_{n}\right),
$$

a value $x_{i}$ of each variable $X_{i}$ is generated with the program function and the value of the dependent variable $y=f\left(x_{1}, \ldots, x_{n}\right)$ is computed.

This procedure is repeated many times so that a statistically significant sample of forecasts for the variable $Y$ is obtained. This sample is used for computing an approximation for the expected value and the confidence interval of random variable $Y$ that corresponds to a given probability $\alpha$. The values $y_{s}$ in the sample are sorted, and the largest and smallest $m$ values are dropped, where $m$ is determined so that the ratio of $m$ by the total number of sample values is as close as possible to $(1-\alpha) / 2$. The difference between the remaining smallest and the remaining largest value is the estimate for the width $2 d$ of the interval where the dependent variable $Y$ will have value with probability $\alpha$.

\section{Method of possible values}

Let the dependent variable $Y$ again be a function of $n$ random variables $X_{1}, \ldots, X_{n}$,

$$
Y=f\left(X_{1}, \ldots, X_{n}\right) .
$$

If the value of $X_{i}$ is on the confidence interval $\left[E\left(X_{i}\right)-d_{i}, E\left(X_{i}\right)+d_{i}\right]$ with a given probability $\alpha$ for each $i=1, \ldots, n$ then the confidence interval of the dependent variable $Y$ is estimated in the following way. Let $f_{\min \alpha}$ be the minimal and $f_{\max \alpha}$ the maximal value of the function $f\left(x_{1}, \ldots, x_{n}\right)$ where $x_{i} \in\left[E\left(X_{i}\right)-d_{i}, E\left(X_{i}\right)+d_{i}\right]$ for each $i=1, \ldots, n$. Then the value of the dependent variable $Y$ will be on the interval $\left[f_{\min \alpha}, f_{\max \alpha}\right]$ with probability at least $\alpha$. The probability that the value of $Y$ is on the interval $\left[f_{\min \alpha}, f_{\max \alpha}\right]$ can be greater than $\alpha$ since its values can be on this interval also for some values of the independent variables $x_{i}$ which are not on the given confidence intervals. This method thus gives an upper bound, and the true confidence interval of $Y$ can be narrower.

\section{ACKNOWLEDGEMENT}

We are especially grateful to Neza Mramor-Kosta for her very helpful comments and discussion. 


\section{REFERENCES}

Anderson, R. D., Sweeney, D. J. and Williams, A. T. (1995): Quantitative Methods for Business. 6th ed., New York: West Publishing Company.

Arrau, P. and Schmidt-Hebbel, K. (1993): Macroeconomic and Intergenerational Welfare Effects of a Transition from Pay-As-You-Go to Fully-Funded Pension Systems. Paper presented at the XIIth Latin American Meeting of the Econometric Society, Tucuman, 17-20 August.

Bernheim, B. D. and Levin, L. (1989): Social Security and Personal Saving: An Analysis of Expectations. The American Economic Review, 79: 2, pp. 97-102.

BS 1997. Bilten Banke Slovenije št. 10 (Monthly Bulletin of Bank of Slovenia). Ljubljana: Banka Slovenije.

BS 1999. Bilten Banke Slovenije št. 5 (Monthly Bulletin of Bank of Slovenia). Ljubljana: Banka Slovenije.

BS 2000. Bilten Banke Slovenije št. 3 (Monthly Bulletin of Bank of Slovenia). Ljubljana: Banka Slovenije.

Chand, K. S. and Jaeger, A. (1996): Aging Population and Public Pension Schemes. IMF Occasional Paper 147, Washington.

Coleman, H. W. and Steele, W. G. Jr. (1989): Experimentations and Uncertainty Analysis for Engineers. New York: John Wiley \& Sons.

Corsetti, G. and Schmidt-Hebbel, K. (1995): Pension Reform and Growth. World Bank Policy Research Working Paper 1471, Washington.

Davis, E. P. (1995): Pension Funds: Retirement-Income Security and Capital Markets. Oxford: Clarendon Press.

Deželan, S. (1996): Efficiency of the Capital Market: Theory, Empirical Research and the Case of Slovenia. Master Thesis. Ljubljana: University of Ljubljana, Faculty of Economics.

EIPF 1999. Gospodarska gibanja (Economic Flows), 301. Ljubljana: EIPF (Ekonomski Inštitut Pravne Fakultete).

European Commission (1999). European Economy, The EU Economy No. 69. Brussels.

Feldstein, M. (1974): Social Security, Induced Retirement and Aggregate Capital Accumulation. Journal of Political Economy, 84, pp. 905-926.

Feldstein, M. (1977): Social Security and Private Saving: International Evidence in an Extended Life Cycle Model. In: Feldstein, M. and Inman, R. (eds): The Economics of Public Services. New York: Macmillan.

Holzmann, R. (1996): Pension Reform, Financial Market Development, and Economic Growth: Preliminary Evidence from Chile. IMF Working Paper 5447, Washington.

Johnson, A. R. and Wichern, W. D. (1992): Applied Multivariate Statistical Analysis. 3rd ed., Englewood Cliffs: Prentice Hall.

Joksimovič, D., Mramor, D. and McGoun, G. E. (1998): How Uncertain is Firm Valuation? Ljubljana: University of Ljubljana, Faculty of Economics, Department of Finance. Mimeo.

MDDSZ 1997. White Paper of the Pension and Invalidity Reform. Ljubljana: Ministrstvo za delo, družino in socialne zadeve (Ministry of Labor, Family and Social Affairs).

Mramor, D. (ed.) (2000): The Capital Market in Slovenia. Ljubljana: Gopodarski Vestnik.

Munnell, A. H. and Yohn, F. O. (1992): What is the Impact of Pensions on Saving? In: Bodie, Z. and Munnell, A. H. (eds): Pension Policy: An International Perspective. Washington: US Government Printing Office.

Shah, H. (1996): Towards Better Regulation of Private Pension Funds. Washington: World Bank. SURS 1998. Statistical Yearbook 37th issue. Ljubljana: SURS (Statistični urad Republike Slovenije).

Acta Oeconomica 51 (2000/2001) 
Threadgold, A. R. (1980): Personal Savings: The Impact of Life Assurance and Pension Funds. Bank of England Discussion Paper, London.

Vittas, D. (1992): Contractual Savings and Emerging Securities Markets. Policy Research Working Paper 858, Washington.

Vittas, D. (1995): Pension Funds and Capital Markets. Public Policy for the Private Sector. Washington: The World Bank.

World Bank (1994): Averting the Old Age Crisis. A World Bank Policy Research Report, Oxford: Oxford University Press.

ZPIZ (1997): Aktualne statistične informacije za mesec maj 1997 (Current Statistical Information for May 1997), Ljubljana: Zavod za pokojninsko in invalidsko zavarovanje Slovenije. 
